\title{
Influência da idade da matriz sobre a biometria de órgãos e a morfometria da mucosa do intestino delgado dos pintos à eclosão
}

\section{Influence of breeder age on biometrics organ and morphology of the mucosa of the small intestine of chicks hatching}

\author{
Jovanir Inês Müller Fernandes ${ }^{1 *}$; Jean Paulo Contini²; Lidiane Boareto Scapini³; \\ Tiago Jacob Gurski²; Aline Fernanda Gonçalves Esser ${ }^{3}$; \\ Alexandre Leseur dos Santos ${ }^{4}$
}

\begin{abstract}
Resumo
O experimento foi conduzido com o objetivo de avaliar o efeito de diferentes idades de matrizes sobre a biometria de órgãos e a morfometria intestinal de pintos de corte à eclosão. Foram incubados 200 ovos provenientes de matrizes pesadas da linhagem comercial Ross 308, com as idades de 32, 40, 48, 56 e 64 semanas. À eclosão 20 pintinhos de cada idade de matriz foram pesados individualmente e sacrificados para avaliação do peso do peito, bolsa cloacal, saco da gema e intestino delgado e do comprimento do intestino delgado. O segmento do duodeno foi coletado para mensuração da altura de vilo e da profundidade de cripta. Houve efeito linear positivo da idade da matriz $(\mathrm{p}<0,05)$ sobre o peso vivo, peso absoluto e relativo do saco da gema, peso absoluto da bolsa cloacal e peso absoluto e relativo do peito. Para o peso absoluto, peso relativo do intestino delgado observou-se efeito quadrático da idade da matriz $(\mathrm{p}<0,05)$, sendo o melhor desenvolvimento do intestino em pintos provenientes de matrizes entre 40 e 50 semanas. $O$ peso do pinto apresentou correlação positiva com o peso do saco da gema, bolsa cloacal e peito $(\mathrm{p}<0,05)$. Para vilo e cripta obteve-se um efeito significativo da idade das matrizes $(\mathrm{p}<0,05)$ sobre a profundidade das criptas, cujo comportamento foi linear decrescente e inverso à idade das matrizes enquanto a relação vilo:cripta, apresentou comportamento linear crescente $(p<0,05)$ de acordo com a idade das matrizes. Conclui-se que a idade da matriz tem influência na biometria dos órgãos e na morfometria da mucosa do intestino delgado de pintos de corte à eclosão.
\end{abstract}

Palavras-chave: Altura de vilo, peso de órgãos, frango de corte, saco da gema

\begin{abstract}
The objective of the conducted experiment was the evaluation of effect of multiple age breeders on the organs biometry and the intestinal morphometry of chicks at hatching. There were incubated 200 eggs provided from Ross 308 breeders at the ages of 32, 40, 48, 56 and 64 weeks. At hatching, 20 chicks of each breeder age were individually weighted and sacrificed in order to evaluate breast, cloacal bursa, yolk sack and small intestine weight, besides the small intestine length. The duodenum portion was collected in order to measure the villus height and the crypt depth. There were a positive linear effect of the breeder age $(\mathrm{p}<0,05)$ on the live weight, absolute and relative yolk sack weight, cloacal bursa

${ }^{1}$ Prof ${ }^{a}$ do Laboratório de Experimentação Avícola, Universidade Federal do Paraná, Setor Palotina, UFPR, Palotina, PR. E-mail:

2 Discentes do Laboratório de Experimentação Avícola, UFPR, Palotina, PR. E-mail: jeancontini@gmail.com; tiagogurski@gmail.com

${ }^{3}$ Discentes de Pós-Graduanção, Laboratório de Experimentação Avícola, UFPR, Palotina, PR. E-mail: lidiscapini@gmail.com;

${ }^{4}$ Prof. da UFPR, Palotina, PR. E-mail: alsantos@ufpr.br
\end{abstract} jimfernandes@ufpr.br alinefesser@gmail.com

* Autor para correspondência 
absolute weight and breast absolute and relative weight. For the absolute and relative small intestine weight it was observed a quadratic effect of the breeder age $(\mathrm{p}<0,05)$, in which the best intestine development was in chicks from breeders between 40 and 50 weeks of age. The chick weight has a positive correlation with the weight of the yolk sac, cloacal bursa and breast $(\mathrm{p}<0,05)$. For the villus and crypt it was obtained a significant effect of the breeders age $(p<0,05)$ on the crypt depth, whose linear behavior was decreasing and inverse to the breeders age. The villus:crypt relation showed a linear increasing behavior $(\mathrm{p}<0,05)$ according to the breeders age. It's concluded that the breeder age has influence on the organ biometry and on the small intestine mucosal morphometry of chicks at hatching.

Key words: Villus height, organ weights, broiler, yolk sac

\section{Introdução}

O efeito do peso do ovo sobre o peso do pinto ao nascer e no seu crescimento subsequente até a idade de abate é a característica mais importante do ponto de vista técnico e econômico. Entretanto, os fatores que controlam a qualidade do pinto não estão claramente definidos e o seu peso pode não estar diretamente associado a sua qualidade. Fatores genéticos da matriz, além das condições fisiológicas no momento da formação do ovo influenciam as características da casca, tais como a condutância, espessura, número e diâmetro dos poros e a composição da gema (CHRISTENSEN; DONALDSON; NESTOR, 1994).

A ovulação ocorre a cada 24 ou 25 horas em matrizes pesadas, logo que atingem a maturidade sexual, porém à medida que as matrizes envelhecem o intervalo entre ovulações aumenta para 26 a 27 horas ou mais, entretanto a mesma quantidade de constituintes da gema, proveniente da síntese hepática é depositada em um número cada vez menor de folículos (ZAKARIA; MIYAKI; IMAI, 1983; VIEIRA, 2000; ROCHA et al., 2008). Assim, ovos produzidos, por matrizes mais velhas, apresentam gemas maiores, proporcionalmente ao peso total do ovo e consequentemente ao tamanho do pinto (MAIORKA et al., 2000).

Além disso, a utilização dos nutrientes pelos embriõesoriundosdeavesmaisvelhas, especialmente de lipídios é mais eficiente quando comparado com embriões de matrizes mais jovens (YAFEI; NOBLE, 1988), contribuindo para a alta taxa de mortalidade embrionária precoce destes embriões. A gema é a principal fonte de energia, via oxidação de ácidos graxos durante o desenvolvimento embrionário e a única fonte de lipídios para o crescimento de tecidos do embrião (POWELL; DEANS; SPEAKE, 2004). Isso tem influência direta no crescimento e o desenvolvimento dos órgãos antes da eclosão.

O trato gastrointestinal, apesar de estar anatomicamente completo no período final do desenvolvimento embrionário, durantes as $72 \mathrm{~h}$ que antecedem a eclosão sofre profundas alterações no desenvolvimento morfológico, bioquímico e celular. De acordo com a disponibilidade de nutrientes na gema o vilo aumenta de 200 a 300\% do $17^{\circ}$ dia de incubação até a eclosão (UNI et al., 2000; PEDROSO et al., 2005a).

Uma questão que ainda não está bem esclarecida é se ovos oriundos de matrizes mais velhas, portanto com maior aporte nutricional podem influenciar o desenvolvimento de vilos e criptas do duodeno. Maiorka (2002) observou maior peso relativo e comprimento de intestino delgado aos sete dias, em pintos provenientes de matrizes de 60 semanas, quando comparado com matrizes de 30 semanas, entretanto, não foi avaliada a morfometria da mucosa do duodeno dessas aves.

O saco da gema é uma membrana vascularizada semelhante à placenta em mamíferos, que envolve a gema durante o desenvolvimento embrionário e é responsável pela transferência de nutrientes para o embrião. Na eclosão, o pinto possui em sua cavidade abdominal um saco de gema residual de aproximadamente $12 \%$ do seu peso (KAWALILAK; ULMER FRANCO; FASENKO, 2010). 
Aliteratura traz resultados divergentes em relação à correlação entre o peso do pinto e do saco da gema. Almeida et al. (2003) concluíram que a idade da matriz não afeta o peso relativo do saco vitelino e que pintos oriundos de matrizes de 60 semanas apresentaram absorção mais rápida das reservas do saco vitelino em relação aos provenientes de matrizes de 30 semanas nas primeiras 24 horas póseclosão.

Desta forma, a biometria dos órgãos á eclosão pode não estar diretamente ligada ao peso absoluto do pinto recém eclodido e ao peso do ovo, mas sim estar mais relacionada ao processo de incubação. Ovos provenientes de matrizes de idades diferentes necessitam do mesmo tempo de incubação e de permanência no nascedouro, mas necessitam de condições distintas de incubação (ALMEIDA et al., 2006; VALLE, 2008). Com a crescente adoção das máquinas de estágio único, as quais permitem controlar precisamente as necessidades gasosas e de temperatura do embrião, torna-se fundamental entender a influência da idade da matriz na morfometria intestinal e a relação no crescimento dos órgãos para o melhor ajuste do perfil de incubação.

O objetivo desse trabalho foi avaliar o efeito da idade da matriz sobre a biometria de órgãos e a morfometria intestinal de pintos de corte à eclosão.

\section{Material e Métodos}

Foram incubados em incubatório comercial 200 ovos provenientes de matrizes pesadas da linhagem comercial Ross 308, com as idades de 32, 40, 48, 56 e 64 semanas, sendo 40 ovos de cada idade de matriz. As matrizes pertenciam a uma agroindústria local com a mesma procedência genética e receberam o mesmo manejo e programa nutricional durante a fase de cria/recria e produção. Os ovos forma incubados em condições semelhantes segundo as recomendações do fabricante das máquinas de incubação.
À eclosão, 20 aves por tratamento foram sacrificadas por deslocamento cervical. Após o sacrifício, as aves foram pesadas individualmente e as carcaças dessecadas para remoção do peito, bolsa cloacal, saco da gema e intestino delgado, que em seguida foram pesados. O peso relativo de cada órgão foi obtido pela fórmula: peso relativo $=$ (peso órgão/peso vivo) x 100. O intestino delgado foi também medido (porção compreendida entre o piloro e a junção íleo-ceco-cólica). O comprimento do intestino delgado foi tomado para a avaliação da densidade do órgão, expressa em gramas por centímetro (peso/comprimento ${ }^{-1}$ ) de acordo com o proposto por Pedroso et al. (2005b).

Foram obtidos fragmentos de aproximadamente $5 \mathrm{~cm}$ de comprimento do duodeno (a partir do piloro até a porção distal da alça duodenal) os quais foram presos abertos longitudinalmente em placas de isopor, e lavados com soro fisiológico. As amostras foram fixadas em solução de Bouin por $24 \mathrm{~h}$ para análise histológica, segundo processos descritos por Beçak (1976). Cada fragmento foi submetido à cortes semi-seriados de $5 \mu \mathrm{m}$ de espessura e corados pelo método da hematoxilina e eosina (HE). Para o estudo morfométrico, as imagens foram capturadas por meio da microscopia de luz (Olympus BX 50), utilizando-se o sistema analisador de imagens computadorizado (Image Pro-Plus - Versão 5.2 Média Cibernética). Foi mensurada a altura de 20 vilos e a profundidade de 20 criptas de cada repetição por segmento e destes valores foi obtida a média.

Os dados foram submetidos à análise de regressão pela decomposição polinomial dos graus de liberdade, referentes à idade das matrizes. As correlações entre o peso do pinto e dos órgãos foram analisadas utilizando o método de Coeficiente de Correlação de Pearson. Todas as análises foram obtidas pelo programa estatístico SAS ${ }^{\circ}$ (2002).

\section{Resultados}

$\mathrm{Na}$ Tabela 1 estão demonstrados os resultados referentes ao peso e a biometria dos órgãos de pintos 
de corte ao nascer oriundos de matrizes de diferentes idades. Houve efeito linear positivo $(p<0,05)$ da idade da matriz para o peso vivo dos pintos à eclosão, peso absoluto e relativo do saco da gema, peso absoluto da bolsa cloacal e peso absoluto e relativo do peito. Para o peso absoluto, peso relativo do intestino delgado e para a densidade intestinal (gramas/centímetro) observou-se efeito quadrático $(p<0,05)$. De acordo com as equações de regressão dessas variáveis, os pintos eclodidos apresentaram o melhor desenvolvimento intestinal quando oriundos de matriz entre 40 e 50 semanas (Tabela 4).

Tabela 1. Peso absoluto e relativo dos órgãos de pintinhos provenientes de matrizes de diferentes idades.

\begin{tabular}{lccccccl}
\hline & \multicolumn{9}{c}{ Idade } & da matriz (semanas) & \multicolumn{2}{c}{ CV (\%) } & efeito \\
\hline & 32 & 40 & 48 & 56 & 64 & & \\
\cline { 2 - 6 } Peso vivo (g) & 42,04 & 44,70 & 47,36 & 50,02 & 52,68 & 2,66 & linear \\
Saco da gema (g) & 3,36 & 3,88 & 4,41 & 4,93 & 5,46 & 21,91 & linear \\
Saco da gema (\%) & 8,28 & 8,80 & 8,72 & 9,48 & 10,86 & 21,45 & linear \\
Bolsa cloacal (g) & 0,56 & 0,61 & 0,65 & 0,69 & 0,74 & 25,03 & linear \\
Bolsa cloacal (\%) & 1,41 & 1,23 & 1,42 & 1,40 & 1,40 & 25,02 & ns \\
Intestino delgado (g) & 1,42 & 1,52 & 1,57 & 1,55 & 1,48 & 14,75 & quadrático \\
Intestino delgado (\%) & 3,36 & 3,25 & 3,35 & 3,19 & 2,71 & 14,48 & quadrático \\
Intestino delgado (cm) & 36,53 & 38,66 & 39,71 & 39,68 & 38,58 & 9,36 & linear \\
Intestino delgado (g cm $\left.{ }^{-1}\right)$ & 52,06 & 57,02 & 62,08 & 63,95 & 55,03 & 20,72 & quadrático \\
Peito (g) & 1,69 & 1,83 & 1,96 & 2,10 & 2,23 & 10,71 & linear \\
Peito (\%) & 3,94 & 4,12 & 4,22 & 4,32 & 4,11 & 10,88 & ns \\
\hline
\end{tabular}

ns: não significativo.

Fonte: Elaboração dos autores.

O peso do pinto eclodido de ovos de matrizes com idades crescentes apresentou correlação positiva significativa $(\mathrm{p}<0,05)$ com o peso da bolsa cloacal, do saco da gema e do peito, entretanto não foi observada correlação com o peso do intestino delgado $(p>0,05)$ demonstrando que este órgão não sofre influência direta da idade da matriz e por consequência do peso do pinto (Tabela 2).

Tabela 2. Coeficientes de correlação de Pearson para o peso do pintinho, do resíduo vitelino, bolsa cloacal e do intestino delgado (ID).

\begin{tabular}{lccccc}
\hline & Peso vivo & Saco da gema & Bolsa cloacal & Peso do ID & Peito \\
\hline Peso vivo & 1,00 & $0,65^{*}$ & $0,34^{*}$ & 0,08 & $0,61^{*}$ \\
Saco da gema & & 1,00 & $0,35^{*}$ & $-0,21$ & $0,50^{*}$ \\
Bolsa cloacal & & & 1,00 & $-0,04$ & $0,22^{*}$ \\
Peso do intestino delgado & & & & 1,00 & $0,15^{*}$ \\
Peito & & & & 1,00 \\
\hline
\end{tabular}

*Correlação positiva e significativa $(\mathrm{p}<0,05)$.

Fonte: Elaboração dos autores. 
Houve efeito significativo $(\mathrm{p}<0,05)$ da idade das matrizes sobre a profundidade das criptas, cujo comportamento (Tabelas 3 e 4 ) foi linear decrescente e inverso à idade das matrizes enquanto a relação vilo:cripta, apresentou comportamento linear crescente $(\mathrm{p}<0,05)$ de acordo com a idade das matrizes.

Tabela 3. Altura de vilo, profundidade de cripta e relação vilo cripta de pintinhos provenientes de matrizes de diferentes idades.

\begin{tabular}{|c|c|c|c|c|c|c|c|}
\hline & \multicolumn{5}{|c|}{ Idade da matriz (semanas) } & \multirow[t]{2}{*}{$\mathrm{CV}(\%)$} & \multirow[t]{2}{*}{ efeito } \\
\hline & 32 & 40 & 48 & 56 & 64 & & \\
\hline Altura de vilo, $\mu \mathrm{m}$ & 202,08 & 200,24 & 229,73 & 206,79 & 178,86 & 27,84 & ns \\
\hline Prof. de cripta, $\mu \mathrm{m}$ & 36,58 & 32,27 & 27,95 & 23,64 & 19,33 & 15,54 & linear \\
\hline Relação vilo:cripta & 5,52 & 6,21 & 8,22 & 8,75 & 9,25 & 16,87 & linear \\
\hline
\end{tabular}

ns: não significativo.

Fonte: Elaboração dos autores.

Tabela 4. Equações de regressão e valores do coeficiente de regressão $\left(\mathrm{R}^{2}\right)$.

\begin{tabular}{llc}
\hline \multicolumn{1}{c}{ Parâmetros } & \multicolumn{1}{c}{ Equações de regressão } & Coeficiente de regressão $\left(\mathrm{R}^{2}\right)$ \\
\hline Peso vivo $(\mathrm{g})$ & $\hat{\mathrm{Y}}=39,3795+0,2066087 \mathrm{x}$ & 0,98 \\
Saco da gema $(\mathrm{g})$ & $\hat{\mathrm{Y}}=1,19073+0,06676 \mathrm{x}$ & 0,97 \\
Saco da gema $(\%)$ & $\hat{\mathrm{Y}}=5,67051+0,07349 \mathrm{x}$ & 0,84 \\
Bolsa cloacal $(\mathrm{g})$ & $\hat{\mathrm{Y}}=0,36+0,00605 \mathrm{x}$ & 0,85 \\
Intestino delgado $(\mathrm{g})$ & $\hat{\mathrm{Y}}=0,07132+0,06164 \mathrm{x}-0,00062051 \mathrm{x}^{2}$ & 0,75 \\
Intestino delgado $(\%)$ & $\hat{\mathrm{Y}}=1,53443+0,09432 \mathrm{x}-0,00117 \mathrm{x}^{2}$ & 0,89 \\
Intestino delgado $(\mathrm{cm})$ & $\hat{\mathrm{Y}}=35,20448+0,07531 \mathrm{x}$ & 0,37 \\
Intestino delgado $\left(\mathrm{g} \mathrm{cm}^{-1}\right)$ & $\hat{\mathrm{Y}}=-22,58376+3,42088 \mathrm{x}-0,03378 \mathrm{x}^{2}$ & 0,87 \\
Peito (g) & $\hat{\mathrm{Y}}=1,11433+0,01811 \mathrm{x}$ & 0,94 \\
Profundidade da cripta, $\mu \mathrm{mm}$ & $\hat{\mathrm{Y}}=53,8347-0,539167 \mathrm{x}$ & 0,98 \\
Relação vilo:cripta & $\hat{\mathrm{Y}}=2,37579+0,105765 \mathrm{x}$ & 0,93 \\
\hline
\end{tabular}

Fonte: Elaboração dos autores.

\section{Discussão}

O peso dos pintos à eclosão têm relação direta com a idade da matriz e com o peso do ovo, conforme já descrito na literatura. (WILEY, 1950; WILSON, 1991; SUAREZ et.al., 1997; TONA et al., 2004; ULMER-FRANCO; FASENKO; CHRISTOPHER, 2010).

Vieira e Pophal (2000) citam que devido às matrizes pesadas consumirem maior quantidade diária de proteína no início da postura, elas produzem albúmen mais espesso, que pode retardar a troca de oxigênio, dificultar a absorção do saco vitelino e piorar assim a nutrição do embrião.

Resultados semelhantes foram encontrados por Luquetti et al. (2004) que trabalharam com matrizes de três idades diferentes (30, 45 e 60 semanas), observaram que reprodutoras mais velhas produzem pintos com maior peso ao nascimento, os quais apresentam também maior peso absoluto de órgãos.

As variáveis peso e comprimento do Intestino delgado e a densidade intestinal (razão do peso e comprimento) apresentaram efeito quadrático sendo que o maior peso e o maior comprimento foram evidenciados em pintos oriundos de matrizes 
entre 40 e 50 semanas, período que corresponde ao pico de eclosão. A falta de correlação (Tabela 4) entre o peso do pinto e o peso do intestino delgado demonstra claramente que o desenvolvimento do intestino delgado é influenciado por outros fatores e não propriamente pelo peso do ovo e do embrião.

Maiorka et al. (2000) concluíram que o intestino delgado dos embriões apresentaram crescimento uniforme, independentemente da idade da matriz até o $21^{\circ}$ dia de incubação, porém, nas primeiras 24 horas pós-eclosão, e na ausência de ração, os pintos gerados de matrizes com 60 semanas de idade tiveram maior comprimento do intestino delgado e peso relativo também maior quando comparados com o intestino dos pintos de matrizes jovens. Traldi (2006) também observou um maior peso do intestino delgado em pintos provenientes de matrizes de 55 semanas.

Pintos maiores provenientes de matrizes mais velhas também apresentaram correlação positiva com o peso do peito, o que pode contribuir com o maior rendimento de carne na idade de abate. Já Dalanesi et al. (2005) concluíram que a idade da matriz não influenciou o peso do peito no primeiro dia de vida, resultados significativos somente foram encontrados aos 49 dias de idade onde peitos de aves provenientes de matrizes de 41 semanas foram mais pesados em relação a matrizes de 68 semanas.

O peso absoluto e relativo do saco da gema apresentou uma relação positiva com o peso do pinto. À eclosão, embriões com maior retenção de gema residual podem indicar que não houve utilização eficiente da energia aí estocada. Embriões de ovos maiores produzem mais temperatura e exigem maiores taxas de renovação do ar e quando essas condições não são atendidas adequadamente a quantidade de oxigênio pode ser insuficiente para o metabolismo energético e, conseqüentemente, comprometer a utilização da gema.

Ovos produzidos por matrizes de idade mais avançada tendem a eclodir mais tarde, em relação ao observado com ovos de matrizes jovens (LIMA;
VIEIRA; CORTELING, 2001).

Neste sentido, os pintos eclodidos de matrizes jovens podem ter utilizado parte do conteúdo do saco da gema uma vez que permanecem por mais tempo nos nascedouros.

A questão da maior retenção do saco da gema é bastante controversa. Ulmer-Franco et al. (2012), relataram sacos de gema maiores em pintos de matrizes de 32 semanas quando comparado às de 40 semanas. Os autores afirmam desconhecer se este resultado se deve ás condições de incubação ou à taxa de absorção da gema que pode ser diferente em pintos de matrizes de idades. Importante destacar que aves com maior retenção de saco da gema têm maior deposição de imunoglobulinas. A imunidade humoral é totalmente dependente da transferência de imunoglobulinas maternas (ROSE; ORLANS; BUTTRESS, 1974).

Por outro lado, no presente trabalho foi observado que os pintos de corte, de acordo com a idade da matriz, apresentaram uma menor utilização da gema durante a incubação (Tabela 1) o que pode ter refletido no comportamento da morfometria intestinal. Pintos eclodidos de matrizes mais jovens apresentaram criptas mais profundas que pintos de matrizes mais velhas Apesar da diminuição da profundidade das criptas em função da idade da matriz, não houve prejuízos na altura do vilo.

Segundo Geyra, Uni e Sklan (2001), as criptas intestinais de pintos à incubação não estão totalmente definidas e ao longo das primeiras 24 horas póseclosão se desenvolvem em distintas estruturas. O aumento na profundidade da cripta está relacionado ao aumento da capacidade absortiva do vilo e a taxa de renovação celular (UNI; PLATIN; SKLAN, 1998; UNI et al., 2000).

Células da cripta têm capacidade de regenerar a mucosa intestinal muito rapidamente, fato importante para que ocorra absorção e proteção do pinto recémeclodido. Para a relação vilosidade/cripta intestinal e desejável que as vilosidades apresentem-se altas e as criptas rasas (NABUURS, 1995). A profundidade da 
cripta pode indicar o nível de hiperplasia das células intestinais; sendo que a redução da profundidade indica menor nível de agressão a morfologia da parede intestinal (CERA, 1988).

\section{Conclusão}

A idade da matriz tem influência na biometria dos órgãos. $\mathrm{O}$ peso do pinto de matrizes de idades crescente tem correlação positiva com o peso do saco da gema, bolsa cloacal e peito.

As medidas intestinais, como peso, comprimento e a razão entre essas medidas foram maiores para matrizes de idades intermediárias.

A morfometria da mucosa do intestino delgado de pintos de corte à eclosão é influenciada pela idade da matriz, indicando que pintos originados de matrizes mais jovens têm criptas mais profundas que os de matrizes mais velhas, o que pode contribuir para o seu melhor desempenho.

Todos os procedimentos de coleta de material biológico foram aprovados pelo Comitê de Conduta Ética no Uso de Animais em Experimentação da Federal do Paraná - Campus Palotina.

\section{Referências}

ALMEIDA, J. G.; DALHKE, F.; MAIORKA, A.; FARIA FILHO, D. E.; OELKE, C. A. Efeito da idade da matriz no tempo de eclosão, tempo de permanência do neonato no nascedouro e peso do pintainho. Archives of Veterinary Science, Curitiba, v. 11, n. 1, p. 45-49, 2006.

ALMEIDA, J. G.; VIEIRA, S. L.; GALLO, B. B.; CONDE, O. R. A.; OLMOS, A. R. Period of incubation and post-hatching holding time influence on broiler performance. Brazilian Journal of Poultry Science, Campinas, v. 8, n. 3, p. 153-158, 2003.

BEÇAK, W. P. J. Técnicas de citologia e histologia. Rio de Janeiro: Editora Livros Técnicos e Científicos S.A, 1976. v. 1, $306 \mathrm{p}$.

CERA, K. R. Effect of age, weaning and postweaning diet on small intestinal growth and morphology in young swine. Journal of Animal Science, Champaing, v. 66, n. 2, p. 574-584, 1988.
CHRISTENSEN, V. L.; DONALDSON, W. E.; NESTOR, K. E. Incubation temperature effects on metabolism and survival of turkey embryos. In: EUROPEAN POULTRY CONFERENCE, 9., 1994, Glasgow. Proceedings... Glasgow: World's Poultry Science Association, 1994. p. 399-402.

DALANESI, J. A.; MENDES, A. A.; GARCIA, E. A.; GARCIA, R. G.; MOREIRA, J.; PAZ, I. C. L. A. Efeito da idade da matriz sobre o desempenho e rendimento de carcaça de frangos de corte. Arquivos Brasileiros de Medicina Veterinária e Zootecnia, Belo Horizonte, v. 57, n. 2, p. 250-260, 2005.

GEYRA, A.; UNI, Z.; SKLAN, D. The effect of fasting at different ages on growth and tissue dynamics in the small intestine of the young chick. British Journal of Nutrition, Cambridge, v. 86, n. 1, p. 53-61, 2001.

KAWALILAK, L. T.; ULMER FRANCO, A. M.; FASENKO, G. M. Impaired intestinal villi growth in broiler chicks with unhealed navels. Poultry Science, Champaign, v. 89, n. 1, p. 82-87, 2010.

LIMA, A. A.; VIEIRA, S. L.; CORTELING, J. Eclodibilidade de ovos oriundos de matrizes com extremos em idade e pesos diferentes. Revista Brasileira de Ciência Avícola, Campinas, v. 3, n. 3, p. 86-94, 2001.

LUQUETTI, B. C.; GONZALES, E.; BRUNO, L. D. G.; FURLAN, R. L.; MACARI, M. Egg traits and physiological neonatal chick parameters from broiler breeder at different ages. Revista Brasileira de Ciência Avícola, Campinas, v. 6, n. 1, p. 13-17, 2004.

MAIORKA, A. Efeito da idade da matriz e do agente trófico (glutamina) sobre o desenvolvimento da mucosa intestinal e atividade enzimática do pâncreas de pintos de corte na primeira semana. 2002. Tese (Doutorado em Zootecnia) - Universidade Estadual Paulista, Jaboticabal.

MAIORKA, A.; SANTIN, E.; FISCHER DA SILVA, A. V.; BRUNO, L. D. G.; BOLELI, I. C.; MACARI, M. Desenvolvimento do trato gastrointestinal de embriões oriundos de matrizes pesadas de 30 e 60 semanas de idade. Revista Brasileira de Ciência Avícola, Campinas, v. 2, n. 2, p. 141-148, 2000.

NABUURS, M. J. A. Microbiological, structural and functional changes of the small intestine of pigs at weaning. Pig News and Information, Oxfordshire, v. 16, p. 93-97, 1995.

PEDROSO, A. A.; STRINGHINI, J. H.; LEANDRO, N. S. M.; CAFÉ, M. B.; BARBOSA, C. E.; LIMA, F. G. Suplementos utilizados como hidratantes nas fases préalojamentoe pós-alojamento para pintos recém eclodidos. Pesquisa Agropecuária Brasileira, Brasília, v. 40, n. 7, p. 627-632, 2005a. 
PEDROSO, A. A.; STRINGHINI, J. H.; LEANDRO, N. S. M.; XAVIER, A. S.; LIMA, F. G.; BARBOSA, C. E. Desempenho e biometria de órgãos digestórios de frangos provenientes de matrizes jovens após diferentes intervalos de alojamento. Revista Brasileira de Ciência Avícola, Campinas, v. 3, 2005b. Suplemento 5.

POWELL, K. A.; DEANS, E. A.; SPEAKE, B. K. Fatty acid etherification in the yolk sac membrane of the avian embryo. Journal of Comparative Physiology, Marburg, v. 174, n. 2, p. 163-168, 2004.

ROCHA, J. S. R.; LARA, L. J. C.; BAIÃO, N. C.; CANÇADO, S. V.; BAIÃO, L. E. C.; SILVA, T. R. Efeito da classificação dos ovos sobre o rendimento de incubação e os pesos do pinto e do saco vitelino. Arquivos Brasileiros de Medicina Veterinária e Zootecnia, Belo Horizonte, v. 60, n. 4, p. 979-986, 2008.

ROSE, M. E.; ORLANS, E.; BUTTRESS, N. Immunoglobulin classes in the hen's egg: their segregation in yolk and white. European Journal of Immunology, Weinheim, v. 4, n. 7, p. 521-523, 1974.

STATISTICAL ANALYSIS SYSTEM INSTITUTE - SAS. SAS® statistical analysis system user's guide: statistics. Version 9.1.4 ed. Inc., Cary: NC, 2002.

SUAREZ, M. E.; WILSON, H. R.; MATHER, F. B.; WILCOX, C. J.; MCPHERSON, B. N. Effect of strain and age of the broiler breeder female on incubation time and chick weight. Poultry Science, Champaign, v. 76, n. 7, p. 1029-1036, 1997.

TONA, K.; ONAGBESAN, O.; DE KETELAERE, B.; DECUYPERE, E.; BRUGGEMAN, V. Effects of age of broiler breeders and egg storage on egg quality, hatchability, chick quality, chick weight, and chick post hatch growth to forty-two days. Journal of Applied Poultry Research, Champaign, v. 13, n. 1, p. 10-18, 2004.

TRALDI, A. B. Influência da idade da matriz e do peso do ovo incubado nas respostas de pintos de corte alimentados com rações pré-iniciais fareladas, trituradas ou micro peletizadas. 2006. Tese (Doutorado) - Escola Superior de Agricultura Luiz de Queiroz, Universidade de São Paulo.

ULMER-FRANCO, A. M.; CHERIAN, G.; QUEZADA, N.; FASENKO, G. M.; MCMULLEN, L. M. Hatching egg and newly hatched chick yolk sac total IgY content at 3 broiler breeder flock ages. Poultry Science, Champaign, v. 91, n. 3, p. 758-764, 2012.
ULMER-FRANCO, A. M.; FASENKO, G. M.; CHRISTOPHER, E. E. O. Hatching egg characteristics, chick quality, and broiler performance at 2 breeder flock ages and from 3 egg weights. Poultry Science, Champaign, v. 89, n. 12, p. 2735-2742, 2010.

UNI, Z.; GEYRA, A.; BEN HUR, H.; SKLAN, D. Small intestinal development in the young chick:crypt formation and enterocyte proliferation and migration. British Poultry Science, Edinburgh, v. 41, n. 5, p. 544551, 2000.

UNI, Z.; PLATIN, R.; SKLAN, D. Cell proliferation in chicken intestinal epithelium occurs both in the cript and along the villi. Journal Compomparative Physiology, New York, v. 168, n. 4, p. 241-247, 1998.

VALLE, R. Como obter bons pesos na primeira semana em frangos de corte. Campinas: Circular Técnica Aviagen Brasil, fev. 2008.

VIEIRA, S. L. Nutrição neonatal de aves: aspectos práticos, respostas metabólicas e desenvolvimento do sistema imune. In: SIMPÓSIO SOBRE ADITIVOS ALTERNATIVOS NA NUTRIÇÃO ANIMAL, 1., 2000, Campinas. Anais... Campinas: Colégio Brasileiro de Nutrição Animal, 2000. p. 51-64.

VIEIRA, S. L.; POPHAL, S. Nutrição Pós-eclosão de frangos de corte. Revista Brasileira de Ciência Avícola, Campinas, v. 2, n. 3, p. 189-199, 2000.

WILEY, W. H. The influence of egg weight on the prehatching and post-hatching growth rate in the fowl. II. Egg weight: chick weight ratios. Poultry Science, Champaign, v. 29, n. 4, p. 595-604, 1950.

WILSON, H. R. Interrelationship of egg size, chick size, post hatching growth and hatchability. Worlds Poultry Science Journal, Cambridge, v. 47, n. 1, p. 5-20, 1991.

YAFEI, N.; NOBLE, R. C. An electron microscope study of yolk lipid uptake by the chick embryo with particular reference to low hatchability in young parent stock. British Poultry Science, Edinburgh, v. 29, n. 4, p. 887887, 1988.

ZAKARIA, A. H.; MIYAKI, T.; IMAI, K. The effect of aging on the ovarian folicular growth in laying hens. Poultry Science, Champaign, v. 62, n. 4, p. 670-674, 1983. 